\title{
Boxing Practitioners Physiology Review 1. Kinanthropometric Parameters, Skeletal Muscle Recruitment and Ergometry
}

\author{
André Mukala Nsengu Tshibangu \\ Department of Basic Sciences, Faculty of Pharmaceutical Sciences, University of Kinshasa, Kinshasa, Democratic Republic of the \\ Congo \\ Email: andrem36@hotmail.com
}

How to cite this paper: Tshibangu, A.M.N. (2020) Boxing Practitioners Physiology Review 1. Kinanthropometric Parameters, Skeletal Muscle Recruitment and Ergometry. Open Journal of Molecular and Integrative Physiology, 10, 1-24.

https://doi.org/10.4236/ojmip.2020.101001

Received: November 16, 2019

Accepted: January 13, 2020

Published: January 16, 2020

Copyright $\odot 2020$ by author(s) and Scientific Research Publishing Inc. This work is licensed under the Creative Commons Attribution International License (CC BY 4.0).

http://creativecommons.org/licenses/by/4.0/

\begin{abstract}
Seven percent voluntary body weight decrease by boxers requires 21 days while 4.4 percent increase needs only one day. Energy and fluid intakes reduction does not affect boxers punching force. Boxers effective punch masses and body weights correlate. Wrist girths and competition rankings of boxers correlate. Boxers show leanness body fat percentage. Boxers, generally highly mesomorphic, with increasing body weight, show ectomorphy decreases but endomorphy and mesomorphy increases. Vibration treatment enhances power in boxers arm flexors. Presence, nature and thickness of bandages and gloves donned influence boxers punch force. Stance posture adopted by boxers ends in locomotion functional parameters adaptations. Muscular recruitment sequence during rear straight punches may be influenced by the target height (head or body levels) and the boxer intention (produce maximal force or maximal speed). Handgrip strength: 1) increases from younger to older and from lighter to heavier boxers, and 2) correlates with competition ranking. Rear knee extension increases rear straight punching force to the head. Compared to uppercut and straight punches, the hook produces the highest change in hand velocity. Maximal forces are larger for the rear than the lead hand, and greater in more than in less experienced boxers. Hook punch force is greater than those of uppercut and straight punches. Boxer aim (produce maximum force or maximum speed) influence his punching force. Massage neither prevents a decrement in repeated performance nor has detrimental effects on performance, but increases recovery perceptions, compared with the passive rest intervention.
\end{abstract}

\section{Keywords}

Boxing, Integrative Physiology, Martial Arts, Molecular Physiology, Musculoskeletal Physiology 


\section{Introduction}

Physiology is a biological science that deals with functions of living organisms.

Boxing concerned in the present study is the combat sport where attacking weapons are the fists which must be landed to the opponent's legal targets. The targets comprise the anterior and lateral surfaces of the head, the neck and the trunk, surfaces that lie from the face to an imaginary line that links the top of both iliac crests through a transverse plane.

The human body functions may be influenced by physical activity either as responses or as adaptations to the activity.

The present study carries out the task of gathering and commenting available and pertinent information on boxing practitioner physiology.

For that, the keywords "boxing" and "physiology" have been entered in Google and Medline search engines. However, other sources of information have also been consulted: books, journal papers, etc.

\begin{tabular}{|c|c|}
\hline \multicolumn{2}{|c|}{ Keywords "Boxing" and "Physiology", or Concepts Related to Those Keywords } \\
\hline | & 1 \\
\hline Google and Medline Search Engines & $\begin{array}{c}\text { Printed Documents } \\
\text { (Books, Journal Papers, etc) }\end{array}$ \\
\hline$\downarrow$ & $\downarrow$ \\
\hline $\begin{array}{l}\text { Journal Papers Abstracts and/or } \\
\text { Full-Texts Contents }\end{array}$ & Printed Documents Contents \\
\hline \multicolumn{2}{|c|}{ Pertinence Analysis } \\
\hline$\downarrow$ & $\downarrow$ \\
\hline Pertinent & Not Pertinent \\
\hline$\downarrow$ & $\downarrow$ \\
\hline Literature Selection & Literature Rejection \\
\hline
\end{tabular}

Information gathered and commented may be summarized as follows.

2. Kinanthropometric Parameters, Skeletal Muscle Recruitment, and Ergometry

2.1. Kinanthropometric Parameters

2.1.1. Posture

2.1.2. Body Weight Changes

2.1.3. Body Fat Percentage

2.1.4. Wrist Girth

2.1.5. Somatotype

2.2. Skeletal Muscle Recruitment

2.3. Ergometry

2.3.1. Force and Strength

1) Handgrip Strength

2) Effective Punch Mass

3) Rear Hand vs. Lead Hand 
4) Hook vs. Uppercut and Straight

5) Head vs. Body

6) Intention

7) Knee Extension

8) Bandages

9) Dietary Behavior

10) Massage

11) Additional Force Values

2.3.2. Velocity

2.3.3. Power

2.3.4. Additional Ergometry Values

2.4. Suggestions to Boxing Contributors Reminder

\section{Kinanthropometric Parameters, Skeletal Muscle Recruitment, and Ergometry}

\subsection{Kinanthropometric Parameters}

Anthropometry is the science of measurement applied to the human body [1].

Kinanthropometry [2]: 1) bases its judgments on biometric measurements (anatomical data) of a subject with the purpose of drawing conclusions on his morphology, proportionality, body composition, maturity and development; 2) may be considered as a connection between anatomy and physiology, as it deals with quantitative relationship between structure and function; and 3) places the sportsperson in centers of attention (objectives) and, basing itself upon other disciplines (mathematics, physics, statistics, computing ...) assesses nutritional state, growth, physical fitness, training ... of the sportsperson.

\subsubsection{Posture}

Posture is the way someone positions his body when sitting or standing [3]. Out of exchange phases, when neither attack nor defense movements are performed, the boxer assumes a posture referred to as the stance. The stance posture must be held by the boxer whenever he begins or ends an exchange phase (attack and/or defense phases).

Boxers are encouraged to adopt as stance a slight forward-lent posture, trunkbent, lower limbs half-slit with either the left led or the right led, and wearing up to $0.5 \mathrm{~cm}$-heeled shoes [4]. In the aim of facilitating the defense of chest and abdomen legal targets, the trunk surface is offered to the opponent's sight, not totally facing the latter but only showing its three quarters, thanks to lead shoulder forward positioning and the rear shoulder backward positioning. With the purpose of facilitating the defense of the head and neck, the face faces the opponent, the lead hand is placed near the inferior eyelid of the lead body side, the rear hand is placed near the temple of the rear body side, while the chin touches the chest. Physically, the keystone of the boxer's posture, that expresses itself generally during his stance, is located in the boxer's hip [4]. 
Concerns of sound energy management, balance, efficient performance and safety of the boxer may probably have directed the suggestion of the stance above described. However, people acquire postural habits by repeating the same body alignment on many occasions [5]. If body segments are held out of alignment for extended periods of time, the surrounding musculature rests in a lengthened or shortened position [5]. This can give rise to "adaptive shortening" or "stretch weakness" or both [5].

A boxing practice-related adaptation is illustrated by the fact that a locomotor system functional parameters analysis yielded significant differences between 11 young boxers (age: $14.6 \pm 0.6$ years; $7.3 \pm 0.6$ training units per week) and a control group made of 52 male pupils (age: $15.4 \pm 0.4$ years) [6]. Head and shoulder of the boxers were "ventralised" more often $(\mathrm{p}<0.01)$. Highly significant group differences in the bilateral position of the shoulder heights and the iliac crests were detected in the frontal plane. On average, the active maximal rotation of the boxers was decreased by 17.8 degrees $(p=0.006, d=0.800)$.

\subsubsection{Body Weight Changes}

Weight is how heavy something is when it is measured [3].

In boxing, a weight-category sport, athletes attempt to gain a competitive advantage by making the lowest weight category possible [7].

In 82 Senior England international amateur boxers [8], boxers from all weight categories (excluding super-heavyweight) experienced a $7.0 \% \pm 0.8 \%$ decrease in body weight over a 21-day pre-contest period. Following a 24-hour recovery period, eight Senior boxers increased their body weight by $4.4 \% \pm 3.3 \%$ and nine Junior boxers by $5.1 \% \pm 2.3 \%$ [8]. See Table 1 .

Boxers would better take those average values into account before deciding the weight division in which they would like to belong during the coming competitions.

\subsubsection{Body Fat Percentage}

Relative percentage of fat body mass, along with that of fat-free body mass, can express basic body composition in a two-compartment model [9].

Excess body fat does not contribute to work output [10]. It also acts as dead weight in activities where body mass must be lifted repeatedly against gravity in

Table 1. Mean Values of Body Weight Percentage Variations.

\begin{tabular}{ccc}
\hline \multirow{2}{*}{ Day } & \multicolumn{2}{c}{ Body Weight Percentage Variation } \\
\cline { 2 - 3 } & Senior Boxers & Junior Boxers \\
\hline-21 & $0 \%$ & $0 \%$ \\
1 & $-7 \%$ & $-7 \%$ \\
\hline
\end{tabular}

Seven percent decrease needs 21 days efforts but only one recovery day yields increases of 4.4 percent in Senior and 5.1 percent in Junior boxers. 
locomotion during play [11].

In boxing, work output is essential and upper limbs are repeatedly moved against gravity in the stance and while attacking, defending or doing both simultaneously. Normal or lower than normal body fat percentage values are thus expected to be shown by boxers.

Mean body fat values of $6.9 \% \pm 1.6 \%$ have been found in American male boxers participating in Olympic events [12] and those of $9 \%-10 \%$ have been reported in 29 Senior and Junior England international amateur boxers [8].

A comparison made between 11 female boxers and physically active female controls with low $(n=16)$ or average $(n=17)$ fat mass showed that the two former groups had a significantly $(\mathrm{p}<0.001)$ lower fat percentage than the latter: $14.6 \% \pm 2.0 \%, 15.5 \% \pm 4.2 \%$ and $25.8 \% \pm 3.4 \%$, respectively [13]

A consensus opinion for an exact percentage body-fat value associated with optimal health risk has yet to be defined; however, a range $10 \%$ to $22 \%$ and $20 \%$ to $32 \%$ for men and women, respectively, is considered satisfactory for health [9]. Percentages shown by the boxers male as well as female are hence those of leanness.

While an increase in habitual physical activity, through fitness training programs, has been shown to decrease body fat in male subjects, the available evidence suggests that similar changes in body composition may not occur so readily in females [14]. That may explain the relative lower body fat percentages found in male compared with those found in female boxers. See Figure 1.

To make their weight limits before competition, boxers would better lose weight by decreasing superfluous body fat instead of cutting down on fluids, in order to avoid impaired performance resulting from the forced dehydration. Nevertheless, female boxers must take into account the fact that [13] low body fat mass is related to oligomenorrhea.

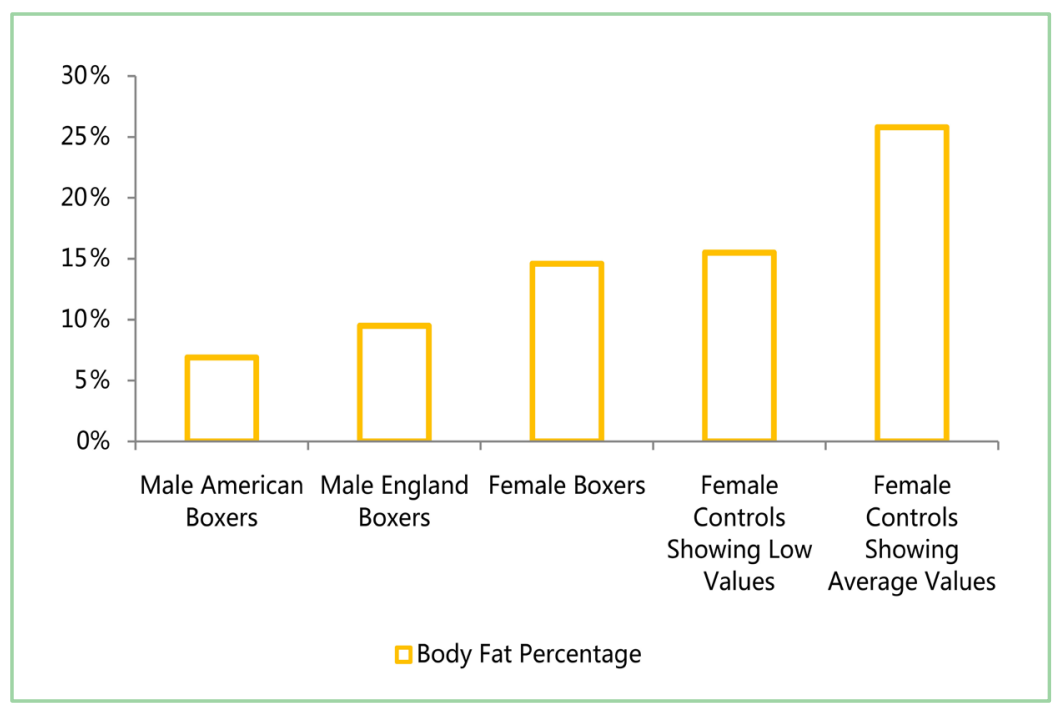

Figure 1. Mean Values of Body Fat Percentage. The values increase in the following sequence: male American boxers $\rightarrow$ male England boxers $\rightarrow$ female boxers $\rightarrow$ female controls with low values $\rightarrow$ female controls with average values. 


\subsubsection{Wrist Girth}

Girth is the size of something or someone large when one measures around them rather than measuring their height [3].

The variable concerned with here is the minimum wrist girth distal to the styloid processes, with the forearm supinated and the hand relaxed [15].

Wrist girth $(17.6 \pm 0.6 \mathrm{~cm})$ has been found related $(\mathrm{r}=0.78, \mathrm{p}<0.05)$ to boxing competition ranking as showed by a Spearman rho correlation analysis of the data obtained in 8 middleweight class elite Italian amateur boxers [first series AIBA (“Association Internationale de Boxe Amateur") ranking] [16]. The first ranked boxer has the highest score gained participating in international tournaments of the AIBA, the World amateur boxing association.

The positive correlation that links AIBA ranking and wrist girth may contribute to foreseeing and thus preventing a possible fall in a boxer ranking. For that, girth measurement should be made at the beginning of a sporting season with the purpose of comparing to subsequent measurements.

\subsubsection{Somatotype}

The somatotype is a quantified expression or description of the present morphological conformation of a person [17]. It consists of a three-numeral rating, for example 3.5-5-1 [17]. The three numerals are always recorded in the same order, each describing the value of a particular component of the physique [17]. In the Heath-Carter method the somatotype components are defined as endomorphy (the relative adiposity of a physique), mesomorphy (the relative musculoskeletal robustness of a physique) and ectomorphy (the relative linearity or slenderness of a physique) [17].

Boxers show increases in endomorphy and mesomorphy and a decrease in ectomorphy as body weight increases: 1.5-5.0-3.0 (<60 kg), 2.0-5.5-2.5 (60 - 79.9 $\mathrm{kg})$ and 2.5-6.0-2.0 (80 - 89.9 kg) [17]. Those values were obtained in high level male boxers. See Figure 2.

Despite the fact that in Indian National male boxers, the Junior have shown an ectomorphic body conformation, contrary to the Senior who have shown a mesomorphic one, the somatotype variation follows the above signaled variation according to the weight [18]. Data presented as means $( \pm \mathrm{SD})$ were $1.8(0.5)-3.2$ (0.6) - $4.0(0.8)$ vs. $2.3(0.6)$ - 4.9 (0.7) - 2.3 (0.8) for 53.6 (4.1) kg (30 Junior boxers) vs. 76.7 (10.9) $\mathrm{kg}$ (30 Senior boxers), respectively.

The somatotype ratings above mentioned show that boxers generally are highly mesomorphic and that with increasing body weight, there are increasing endomorpphy, increasing mesomorphy and decreasing ectomorphy.

High mesomorphy rating is mainly due to the fact that [17] strength, power, speed and agility are very basic to the boxers.

Contrary to muscle mass, superfluous body fat acts as a dead weight and may probably contribute to boxing velocity decrease in heavy boxers compared to lighter. That may be reflected in the lesser endomorphy found in boxers of body weight $<60 \mathrm{~kg}$, compared to heavier boxers' endomorphy [17]. Increasing mesomorphy 


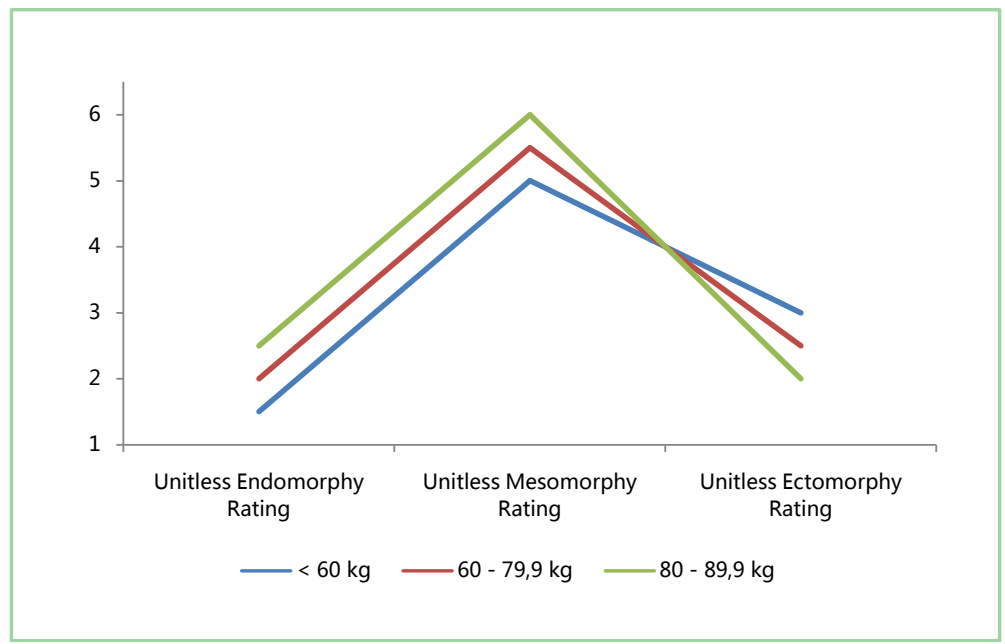

Figure 2. Mean Values of Somatotype Ratings. Boxers are highly mesomorphic and, with increasing body weight, they show increasing endomorphy, increasing mesomorphy and decreasing ectomorphy.

with weight may be reflected in the following: in the Indian male boxers above mentioned, the Junior (ectomorphic and lighter) showed back strength $(\mathrm{kg})$, right hand grip strength $(\mathrm{kg})$, left hand grip strength $(\mathrm{kg})$ and anaerobic power $\left(\mathrm{W} \cdot \mathrm{kg}^{-1}\right.$ BW) values of 125.7 (6.4), $45.6(6.5), 44.9$ (4.6) and 4.9 (0.7), respectively vs. 156.5 (8.6), 62.7 (4.8), 50.1 (3.8) and 6.5 (0.5), respectively, shown by the Senior (mesomorphic and heavier) [18]. The differences were significant $(\mathrm{p}<0.001)$. See Figure 3.

To adapt the somatotype of a practitioner to the ideal somatotype of boxing practitioners, 1) endomorphy could: a) be decreased by increasing aerobic exercise volume and/or reducing food intake, but b) increased via calorie intake increase, while 2) mesomorphy may be increased via strength training as [19] it may result in muscle development.

\subsection{Skeletal Muscle Recruitment}

Recruitment refers to the involvement of motor units in a given muscle contraction from both the qualitative (which) and the quantitative (how many motor units) standpoints [20].

Some muscles engaged in a boxer performance have been determined [21]: while landing straight blows, the triceps brachii is most important; while delivering uppercuts and roundhouse swings, the flexors of the arm and the muscles that move the arm anteriorly are significant participants; for keeping up the lead arm, the deltoid and the flexors of the arm; for both supporting his own blows, resisting the blows of the opponent, bobbing, weaving and ducking, the back and abdominal muscles; in the "follow-through" after a blow, the extensors of the hip, extensors of the knee, and flexors of the ankle are of great importance.

Electromyography (EMG) has proved useful in identifying the specific muscle involvement and in establishing the sequences of muscles while performing sports 


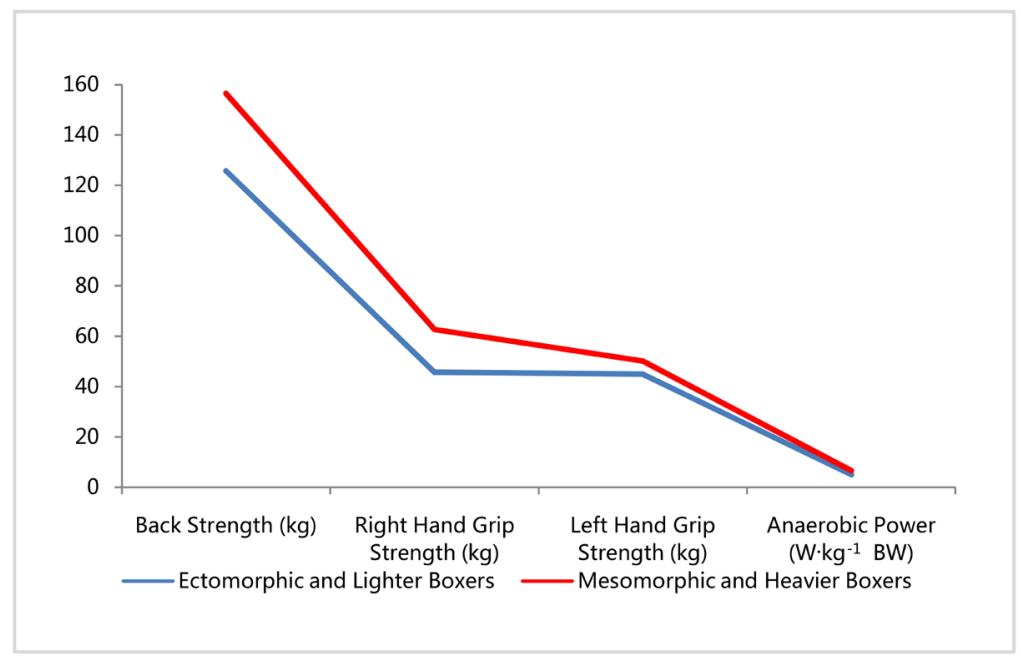

Figure 3. Mean Values of Back Strength, Right Handgrip Strength, Left Handgrip Strength and Anaerobic Power. All the values increase from ectomorphic and lighter to mesomorphic and heavier boxers.

skills, what allow to isolate the muscles in specific training drills, to design training programs and fitness test batteries, as well as the extent to which available training devices faithfully represent the muscle activity of the concerned sport [22].

A study [23] was undertaken with the objective of identifying the muscular recruitment sequence of key muscles relevant to punch performance during rear straight punches delivered at maximal force or maximal speed to the body or the head of a dynamometer manikin by six male competitive amateur boxers (mean \pm SD age: $24.6 \pm 3.3$ years; height: $1.82 \pm 0.05 \mathrm{~m}$, and mass: $73.3 \pm 19.0 \mathrm{~kg}$ ). The subjects wore $0.284 \mathrm{~kg}$ Top Ten competition gloves over their normal hand bandages, and adopted a left hand and rear right hand boxing style. Eight muscles on the rear right hand side of the body were selected for their action and investigated using electromyography: gastrocnemius (G: plantar flexion of foot and knee flexion), biceps femoris (BF: hip extension and knee flexion), rectus femoris (RF: hip flexion and knee extension), upper trapezius ( $\mathrm{T}$ : elevation of the scapula), anterior deltoid (AD: arm flexion and horizontal adduction), biceps brachii (BB: elbow flexion and supination of the forearm), flexor carpi radialis (FCR: wrist flexion and wrist abduction) and triceps brachii (TB: elbow extension). The height of the boxing dynamometer manikin, which was to be the target during each boxing trial, was matched to each subject's shoulder height from the floor.

The results showed a similarity in the early muscular recruitment sequence. The similarity was influenced by the target (manikin head or manikin body) as well as by the boxer intention (landing fists with maximal force or with maximal speed): 1) when the target was the head, the sequence began by $G$, while when the target was the body, the sequence began by RF-G-BF; 2$)$ the mean ( \pm SE) uniaxial punching forces values were a) $3956 \pm 110 \mathrm{~N}$, the intention being the maximal punch force to the head; b) $2459 \pm 61 \mathrm{~N}$, the intention being the maximal speed to the head; c) $3244 \pm 48 \mathrm{~N}$, the intention being the maximal punch force to the body; and d) $2256 \pm 44 \mathrm{~N}$, the intention being the maximal speed to 
the body. See Figure 4 and Figure 5.

Fist landing derives from what is referred to as an open kinetic chain [24]: fist motion is allowed by body segments connected such as the motion of each segment causes motion at other segments in a predictable way, from the proximal segment that remains fixed to the distal segment that moves. The last mentioned is either the fist or the complex made of fist and forearm while the proximal segment may be, in its case, the foot, the lower limb or the whole body, save the upper limb used.

As is the case while performing a job task [25], various joints of the concerned kinetic chain act in concert to facilitate the closed fist landing: lower limbs parts (ankle, knee, hip) allow positioning of the body in the suitable position; the thoracic and lumbar spine flexion and/or rotation position the upper limbs in the appropriate boxing posture; and the upper limbs position the hands at the final position.

Once the positioning of the hands is complete, which includes the muscular activity to support the upper limb mass, the reserve strength capacity of the involved musculature is now available for work (lifting, pushing, using screwdrivers ...) [25] or for landing a closed fist on somebody.

\begin{tabular}{cccc}
\hline Head & & 1 & \\
Body & 1 & 2 & 3 \\
& Rectus Femoris & Gastrocnemius & Biceps Femoris \\
\hline
\end{tabular}

Figure 4. Influence of Target Height on Early Muscular Recruitment Sequence while Landing Blows. When the target is the head, the sequence begins by the gastrocnemius, while when the target is the body the sequence begins by the rectus femoris $\rightarrow$ gastrocnemius $\rightarrow$ biceps femoris.

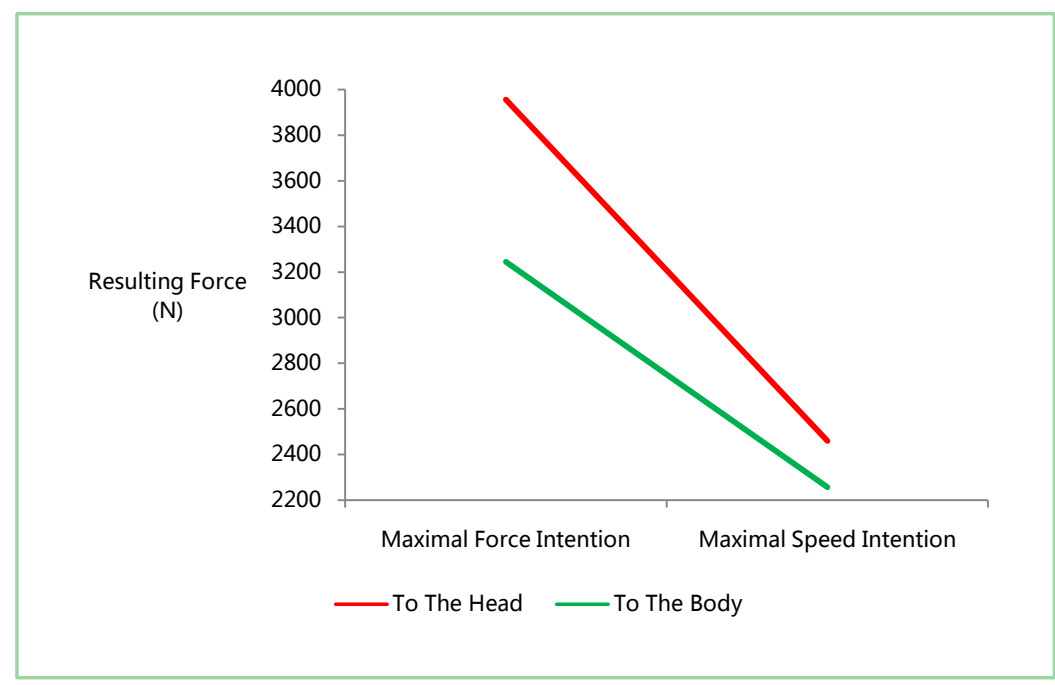

Figure 5. Mean Values of Punching Force when Influenced by the Boxer's Intention. Values are higher when the intention is maximal force production than when the intention is maximal speed production. 
That explains why in the six male competitive amateur boxers, 1) muscle recruitment begins by $\mathrm{G}$, the gastrocnemius, which allows plantar flexion of the foot and knee flexion when a closed fist has to be landed to the head; and 2) when a closed fist has to be landed to the body, the gastrocnemius, $G$, is preceded in the early sequence RF-G-BF by RF, the rectus femoris, which allows body positioning in the suitable position by permitting hip flexion.

The decrease of punching forces when landing fists to the body, comparing with when landing them to the head, reminds of what has been found while working on maximum voluntary isometric strength: the need to bend and/or to twist to reach a work piece generally decreased the maximum exertion force, what led the research workers conclude that the details of body configuration can significantly influence maximum voluntary strengths [26]. However, it is worth signaling here that the task of landing a closed fist is an-isometric.

The boxer who lacks endurance would better try to knock out his opponent early in the battle. With that purpose, hitting the head is more helpful to the boxer than hitting the opponent body.

\subsection{Ergometry}

\subsubsection{Force and Strength}

Force is what makes change happen [27]. In order to execute movement techniques, athletes must skillfully apply force-the product of mass and acceleration [28].

1) Handgrip Strength

Strength is the ability to exert force [20]; it is the maximal force that a muscle or muscle group can generate at a specified velocity [20].

A study [18] dealt with on Indian National Camp boxers measured and compared handgrip strength of 30 Junior boxers (17.6 \pm 2.9 years) to 30 Senior boxers (22.1 \pm 3.1 years). Grip strength showed values lower in Junior than in Senior boxers for both right hand $(45.6 \pm 6.5 \mathrm{~kg}$ vs. $62.7 \pm 4.8 \mathrm{~kg} ; \mathrm{p}<0.001)$ and left hand $(44.9 \pm 4.6 \mathrm{~kg}$ vs. $50.1 \pm 3.8 \mathrm{~kg} ; \mathrm{p}<0.001)$. See Figure 6 .

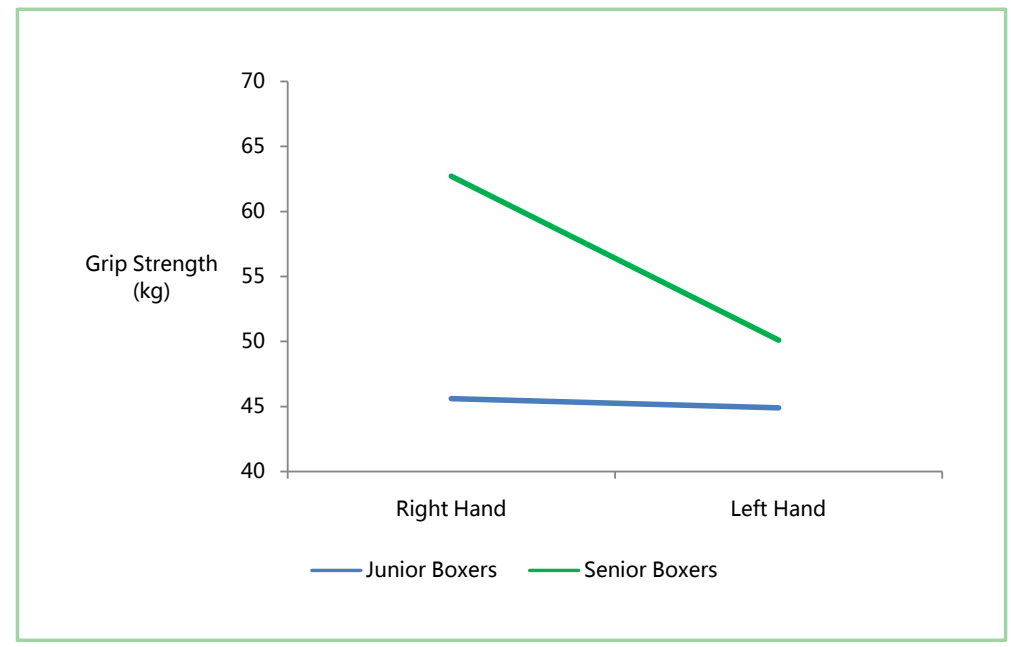

Figure 6. Mean Values of Grip Strength. Grip strength showed values lower in Junior than in Senior boxers for both right hand and left hand. 
In another study, a Spearman rho correlation analysis revealed that the handgrip strength $(58.2 \pm 6.9 \mathrm{~kg}, \mathrm{r}=0.87)$ of the dominant hand was highly related $(\mathrm{p}<$ 0.01 ) to boxing competition ranking in eight elite Italian amateur boxers first series (AIBA ranking) [16]. The authors determined the dominant hand as the favorite hand used to lunge the punch during boxing.

As thought by Khanna and Manna [18], in amateur and professional boxing, power output is essential and related to the force of muscles involved in the movements. Grip strength is thus essential for punching. In the study report, body mass has been cited by the authors to explain the increase or the trend to increase of values from the younger to the older and from the lighter to the heavier boxers. That was expectable as, according to the study results, grip strength vary in the same direction as body mass and lean body mass and as the last mentioned makes expect a variation in the same direction as muscle cross-sectional area [22] and therefore, consistent with a general agreement [29], strength.

A retrospective analysis of handgrip strength measurement values is thus one of the tools that may be used by a coach to assess the suitability of a boxer to meet competition demands. That stays valid for the study carried out on the eight elite Italian amateur boxers, considering that the results show a high link between handgrip strength and boxing competition ranking.

\section{2) Effective Punch Mass}

The effective mass of a boxer's punch may be determined [30] using the following momentum equation where $m_{h}$ is the effective mass of the puncher's hand, $V_{p}$ is the punch velocity, $m$ is the mass of Hybrid III head, and $V_{h}$ is the Hybrid III head velocity.

$$
m_{h} V_{p}=\left(m_{h}+m\right) V_{h}
$$

Straight punch force averaged 3427 (standard deviation (SD) 811) N when landed by seven Olympic boxers from four weight classes to the frangible face of a Hybrid III dummy [30]. The average effective mass of the punch was 2.9 (SD $2.0) \mathrm{kg}$. Jaw load was 876 (SD 288) N. The peak translational acceleration was 58 (SD 13) $\mathrm{g}$, the rotational acceleration was 6343 (SD 1789) $\mathrm{rad} \cdot \mathrm{s}^{-2}$, and neck shear was 994 (SD 318) N. Punch force increased linearly $(r=0.539, \mathrm{p}=0.021)$ with the four weight classes to which belonged the seven boxers (flyweight, light welterweight, middleweight, and super heavyweight). The mean effective mass for all landed punches was 2.86 (SD 2.03) kg. The analysis showed that effective mass had a slight linear association with the weight of the boxer $(\mathrm{r}=0.484, \mathrm{p}=$ 0.042).

The higher punch force of the heavier weight classes was attributed primarily by the authors of the study to the higher effective mass of the punch. That is not in contradiction with the fact that heavier subjects have been found to exert larger horizontal hand forces than lighter [26].

The study offers, among other things, the possibility for developing training techniques aimed to increase punch effective mass and thus punch force. 
3) Rear Hand vs. Lead Hand

Most boxers stand using a stance such as there is lead hand and foot anterior to the body coronal plane as well as rear hand and foot posterior to the body coronal plane. Pre-rotation is thus part of boxer stance.

Body configuration can significantly influence maximum voluntary strength [26]. Body and limb position partly limit and, therefore, determine muscular force and power expression during any type of muscle movement pattern [31].

That is illustrated by the results of a study where comparison of the maximal straight punching forces of seven elite, eight intermediate and eight novice boxers has been made to assess the discrimination efficacy of a boxing dynamometer [32]. The results (mean $\pm s_{\text {mean }}$ ) were $4800 \pm 227 \mathrm{~N}, 3722 \pm 133 \mathrm{~N}$ and $2381 \pm 116$ $\mathrm{N}$ for the rear hand, and $2847 \pm 225 \mathrm{~N}, 2283 \pm 126 \mathrm{~N}$ and $1604 \pm 97 \mathrm{~N}$ for the lead hand. Maximal forces have hence been larger for the rear than the lead hand $(\mathrm{p}<0.001)$; greater in the elite than the intermediate group, and greater in the intermediate than in novice group $(\mathrm{p}<0.05)$. See Figure 7.

As is the case while performing a job task [25], various joints of the concerned kinetic chain act in concert to facilitate the closed fist landing. When the trunk makes part of the kinetic chain, axial rotation may be expected to contribute to the strength considered as the total external moments about each joint [25]. It is thus expectable that maximal forces be larger for the rear hand than for the lead hand as subjects have been found $20 \%$ to $25 \%$ weaker while exerting in the direction of the pre-rotation and 30\% stronger when exerting in the opposite direction, in a study where they performed axial rotation from neutral, $15^{\circ}$, and $30^{\circ}$ rotation to the left and right in the direction of pre-rotation and away from it [33].

"Motor learning" refers to the fact that subjects learn to coordinate the proper muscles involved in a given training, with the resulting improvement of muscle strength, at least in untrained subjects during the first period of training with

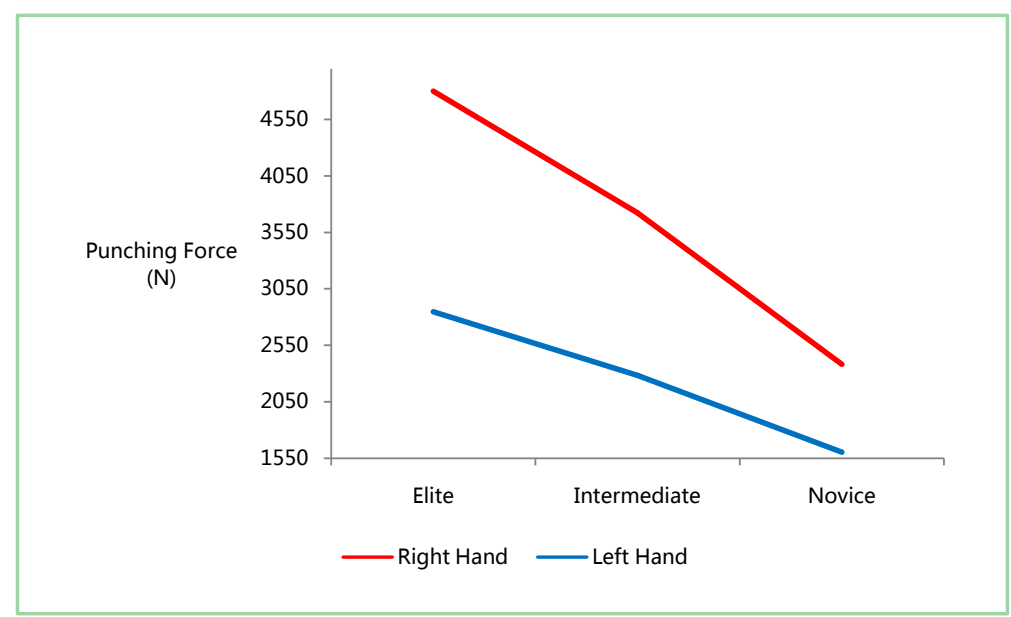

Figure 7. Mean Values of the Maximal Straight Punching Forces. Maximal forces are larger for the rear than the lead hand, greater in the elite than the intermediate group, and greater in the intermediate than in the novice group. 
submaximal loads [29]. It is therefore expectable that less experienced boxers need a muscle strength improvement higher than that of more experienced boxers, and that maximal forces be greater in the elite than in the intermediate group, and greater in the intermediate than the novice group.

When the intention is other than hitting hard the opponent, amateur and professional boxers are advised to use preferably the lead hand. The study results afore mentioned support the advice for safety and for efficiency reasons.

In fact, boxer safety is higher while landing a lead closed fist than while landing a rear closed fist to the opponent because the resulting trunk rotation made in the direction of the pre-rotation decreases the legal target area offered to the opponent's closed fists: landing a rear hand closed fist and its resulting trunk rotation made in opposite direction of the pre-rotation increases the legal target area offered to the opponent's closed fists by unveiling what was covered during the boxer stance by rear forearm and rear arm.

Either for discouraging the opponent from attacking or intending to knock out the opponent, the energy expended by the boxer is higher than the energy expended when the intention is other. So, for not mismanaging energy, the boxers are advised to reserve landing the rear closed fist only for those two purposes. The reason is that of efficiency.

\section{4) Hook vs. Uppercut and Straight}

With the purpose of landing a fist to an opponent, a boxer may use a hook (elbow flexed and forearm totally or partially in pronation), an uppercut (elbow flexed and forearm in supination) or a straight (elbow extended and forearm in pronation).

The functional anatomy of the concerned muscles while landing the three afore mentioned kinds of blows to an opponent may impact on the strength of the latters as has been found in the results of a study that addressed impact biomechanics from boxing punches: hooks, uppercuts and straights have been landed to the forehead and jaw of an instrumented Hybrid III dummy by eleven Olympic boxers weighing 51 to $130 \mathrm{~kg}$ (112 - $285 \mathrm{lb})$ [34]. Instrumentation included translational and rotational head acceleration and neck loads in the dummy. The hook produced the greatest punch force $(4405 \pm 2318 \mathrm{~N})$ with average neck load of $855 \pm 537 \mathrm{~N}$. The resulting head translational and rotational accelerations were $71.2 \pm 32.2 \mathrm{~g}$ and $9306 \pm 4485 \mathrm{r} \cdot \mathrm{s}^{-1}$.

Hook punch force was greater than uppercut punch force: punch force with forearm totally or partially in pronation was higher than punch force with forearm in supination. That reminds of what signaled by Amell: males can exert up to 14 N.m on a handle in pronation and 13 N.m in supination while females can exert approximately $50 \%$ of these values [25].

Hook punch force was greater than straight punch force: punch force with elbow flexed was higher than punch force with elbow extended. That is close to what mentioned by Tyldesley and Grieve: movements with the elbow flexed so that the load arm is short require less effort than those that use the shoulder to 
reach with the extended upper limb (load arm longer) [35].

\section{5) Head vs. Body}

As aforementioned, body configuration can significantly influence maximum voluntary strength [26]. Body and limb position partly limit and, therefore, determine muscular force and power expression during any type of muscle movement pattern [31].

On the one hand, to blow the body, one may either flex the trunk (bend the body) with lower limbs extended, what results in a relative feeble trunk rotation, or increase lower limbs flexion with the resulting relative higher trunk rotation. On the other hand, body asymmetry is higher while blowing the body than while striking the head.

The need to bend and/or to twist to reach a work piece while pushing or pulling in horizontal direction generally decreases the maximum voluntary isometric strength [26]. The trunk rotation is strongest in extension, followed by flexion, lateral flexion, and axial rotation [33], as found in a study conducted to determine arm strength values for isometric and isokinematic efforts around the human trunk. Strength values declined for all handle heights with increasing asymmetry in a work that assessed both isometric and isokinematic push and pull strength at three handle heights $(50,100$, and $150 \mathrm{~cm})$ and three body orientations (sagittal, 30-degree lateral, and 60-degree lateral planes) [26].

All that could make one expect forces generated by punches landed to the head to have higher values than those generated by punches landed to the body. But the below mentioned results of study do not sustain that. However they are consistent with the fact that punching forces from the rear hand have values higher than those from the rear hand, as has been mentioned above (See 3) Rear Hand vs. Lead Hand).

Maximum single punch force for the straight and hook punches to the head and body has been measured (means \pm SD) in 29 Senior England international amateur boxers [8]: the lead hand straight punching force (to the head $1722 \pm$ $700 \mathrm{~N}$ and to the body $1682 \pm 636 \mathrm{~N}$ ) was lower than the straight rear hand (to the head $2643 \pm 1273 \mathrm{~N}$ and to the body $2646 \pm 1083 \mathrm{~N}$ ), lead hook (to the head $2412 \pm 813 \mathrm{~N}$ and to the body $2414 \pm 718 \mathrm{~N}$ ) and the rear hook (to the head 2588 $\pm 1040 \mathrm{~N}$ and to the body $2555 \pm 926 \mathrm{~N}$ ); the subjects characteristics were (means $\pm \mathrm{SD}$ ): $21 \pm 2$ years age, $1.74 \pm 0.8 \mathrm{~m}$ height, $67 \pm 10 \mathrm{~kg}$ mass and $6.2 \pm$ $3.7 \%$ over competition weight. See Figure 8.

\section{6) Intention}

The aim of a boxer (either maximum force or maximum speed) while landing a blow may influence the punching force as showed the results from a work which utilized six male competitive amateur boxers (mean \pm SD age: $24.6 \pm 3.3$ years; height: $1.82 \pm 0.05 \mathrm{~m}$; mass: $73.3 \pm 19.0 \mathrm{~kg}$ ) wearing $0.284 \mathrm{~kg}$ Top Ten competition gloves over their normal hand bandages, and adopted a lead left hand and rear right hand boxing style [23]: the mean ( \pm SE) uniaxial punching forces to the body for maximum force was $3244 \pm 48 \mathrm{~N}$ and for maximum speed 
$2256 \pm 44 \mathrm{~N}$ and to the head $3956 \pm 110 \mathrm{~N}$ and $2459 \pm 61 \mathrm{~N}$, respectively. See Figure 9.

The American boxer Mike Tyson belonged to the heavyweight division, a division in which hard punching is the point [36]. Tyson has given the reason for his possession of what has been qualified by Oates as sledgehammer blows: punches are thrown with a "bad intention in a vital area" [36].

In fact, on 16 February 1986, Tyson broke Jesse Ferguson's nose during the match. To give the reason for the fracture, Tyson said: "because I want to punch the bone into the brain" [36].

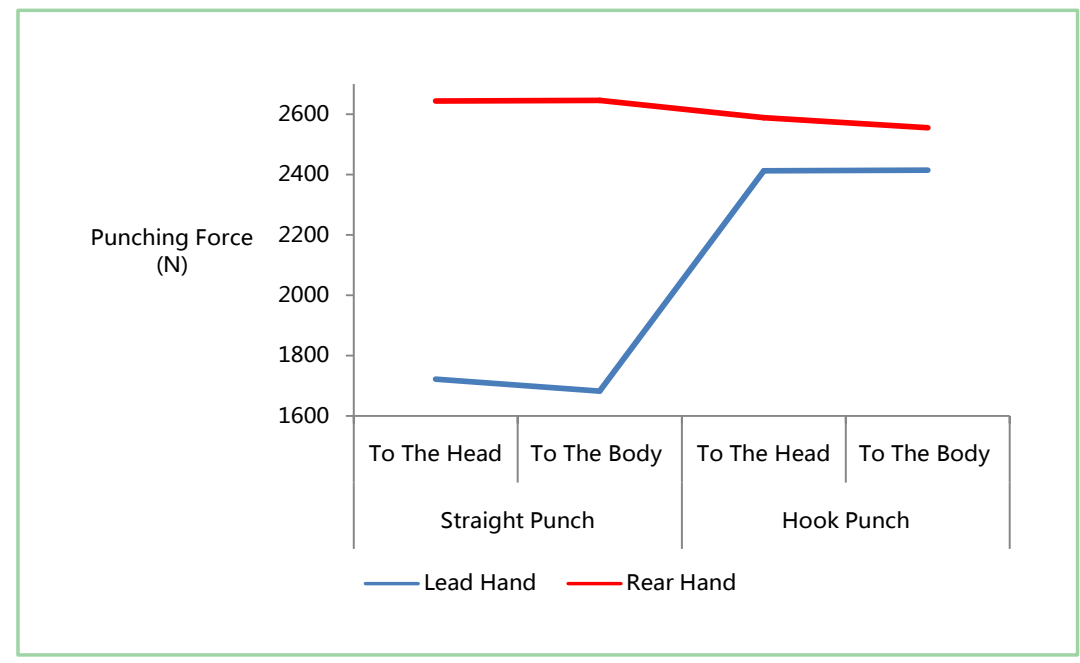

Figure 8. Mean Values of Maximum Punching Force for the Straight and Hook Punches to the Head and to the Body. Forces generated by punches landed to the head do not have values higher than those generated by punches landed to the body, but punching forces from the rear hand have values higher than those from the rear hand.

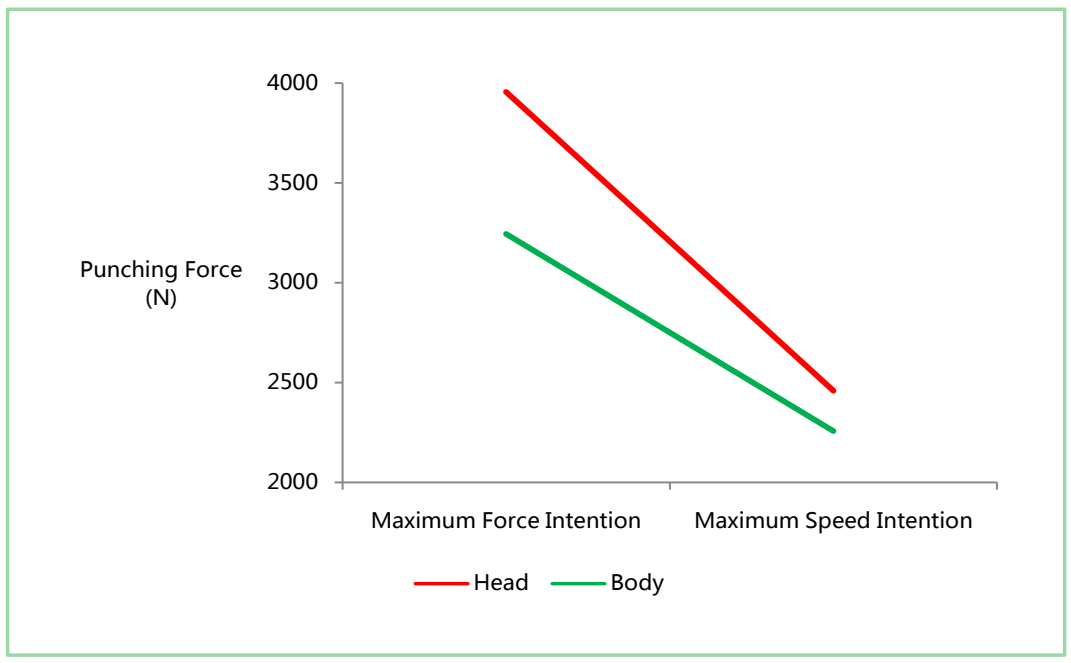

Figure 9. Mean Values of Punching Force when Influenced by the Boxer's Intention. Punching force is higher when the intention is maximum force production than when the intention is maximum speed production. 
On 22 November 1986, Tyson knocked down Trevor Berbick twice during the second round. After trying to rise from the second knockdown, Berbick fell after two intents to. Tyson said afterward that "every punch had a murderous intention". The last blow landed by Tyson was a left hook to right temple of Berbick [36] ("bad intention in a vital area").

The influence of intention is also expressed in the fact that boxers are able to postpone a knockout victory. For example, on 16 October 1987, Tyson knocked out Tyrell Biggs at the seventh round. Post-fight, Tyson said that he could have knocked Biggs in the third round but chose to knock him out slowly "so that he would remember it for a long time" [36]. Tyson added "I wanted to hurt him real bad" [36]. What underlay the postponement was a Tyson's frustration: speaking of Biggs, Tyson said: "He didn't show me any respect." [36].

It is worth signaling that the results here mentioned sustain what expected comparing blows landed to the head with blows landed to the body (See5) Head vs. Body): punching forces are here higher while blowing to the head than blowing to the body.

It appears that, when maximum punch force value is very low, compared to the mean value, a boxer showing the value may improve it by using intention influence on punching force.

\section{7) Knee Extension}

The quadriceps femoris muscle (composed of four separated heads: rectus femoris, vastus intermedius, vastus lateralis and vastus medialis) represents the primary knee extensor, although the tensor fasciae latae also contributes to knee extension [37].

Electromyography has been carried out to investigate recruitment of eight muscles (gastrocnemius, biceps femoris, rectus femoris, upper trapezius, anterior deltoid, biceps brachii, flexor carpi radialis and triceps brachii) during rear hand straight punches delivered to a dynamometer by six male competitive amateur boxers (mean \pm SD age: $24.6 \pm 3.3$ years; height $1.82 \pm 0.05 \mathrm{~m}$; mass: $73.3 \pm 19.0$ $\mathrm{kg}$ ) who wore $0.284 \mathrm{~kg}$ Top Ten competition gloves over their normal hand bandages and adopted a stance with a lead left hand and a rear right hand [23]. Of the eight muscles, rectus femoris has been among the muscles early recruited: fourth for punch delivery with maximal speed to the head, second for punch delivery with maximal force to the head; first for punch delivery with maximal force to the body and also first for punch delivery with maximal speed to the body, i.e. early, more for force than for speed.

When the intention has been maximum force, rear straight punching force to the head took the value of $4202 \pm 1037 \mathrm{~N}$ and rectus femoris muscle activity took the value of $1248 \pm 306 \mu \mathrm{V}$, while lower values have been obtained when the intention has been maximum speed: $2614 \pm 591 \mathrm{~N}$ and $910 \pm 256 \mu \mathrm{V}$, respectively [23]. See Figure 10.

Early rectus femoris muscle recruitment, earlier for maximum force than for maximum speed, as well as concomitant increase of both rear straight head 


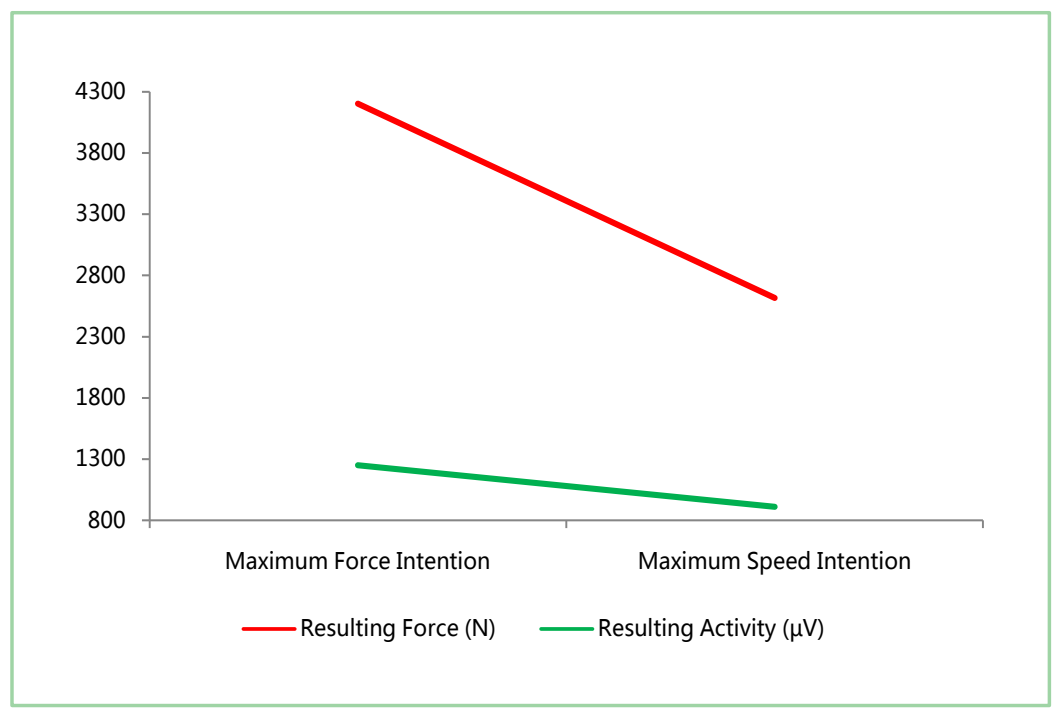

Figure 10. Mean Values of Rear Straight Head Punching Force and Rectus Femoris Activity when Influenced by the Boxer's Intention. Punching force is higher when the intention is maximum force production than when the intention is maximum speed production.

punching force values and rectus femoris activity when the intention has been maximum force, compared to maximum speed, make coaches right when they advise boxers to extend the leg of the same body side while, using the rear hand, they land a straight blow to the opponent's head.

\section{8) Bandages}

Bandaging hands while boxing has been expected to constitute a prophylactic means to the benefit of the attacking boxer [4] as well as the attacked boxer [38].

Bouttier and Lustyk consider the bandage as a convenient setting for the wrist and an efficient protection of the metacarpophalangeal joints [4].

Schmidt-Olsen, Jensen and Mortensen speak of a survey of all amateur boxing matches in Denmark made during a 3-year period that led to the conclusion that unlimited length of bandages, voluntary use of boxing helmets, and heavier gloves for boxers greater than 149 pounds did not affect the frequency of matches being stopped because of knock outs or blows to the head [38].

Unlimited length of bandages is only one of the three mentioned prophylactic intervention means. Maybe, working only on hand bandaging could show better the presence or the absence of the bandaging effect on stopping of the matches. Another thing that must be emphasized is that the effect of a blow depends not only on the blow itself but also on the sensitivity of the boxer attacked.

Kim and Bishu [39] report studies dealing with the effect of glove types on holding force. Thicker gloves have been found to cause the forearm flexors and extensors exert more force. No significant difference has been found when comparing the effect of bare hands with that of hands donning leather gloves. However, significant difference has been found when comparing bare hands effect with that of hands donning cotton gloves. 
While leather gloves remind of boxing gloves, cotton gloves remind of boxers hand bandages.

In boxers, the 6-ounce $(171 \mathrm{~g})$ glove is donned by light flight to light weight boxers; the 8-ounce ( $227 \mathrm{~g}$ ) glove is donned by the welterweight to light heavyweight boxers; and the 10-ounce ( $283 \mathrm{~g}$ ) glove is donned by the heavyweight boxers [4]. It should be noted that lace mass value is excluded from the gloves mass values afore mentioned [4]. The thicker the glove, the more the landed blow impact is spread over a larger area; the thicker glove shakes more than it knocks down instantly [4].

Besides, foam rubber boxing gloves have been found to absorb blows in the order of $80 \%$, while horsehair gloves absorb approximately $37 \%$ [4].

A research aimed to compare the impact forces which could be attained barehanded versus those obtained with different types of bandages made up of gauze and diachylon utilized 22 boxers, measured the impact force with a Kistler force plate covered with a synthetic mattress, and made the workers draw the following conclusions: 1) bandaging increases the rigidity of the hands and facilitates the transfer of the punch impact force in comparison to a similar punch without a bandage or with a thinner one, 2) the force increases in relation to the thickness of the bandage, and 3) the use of additional pieces of diachylon has a greater influence than gauzes [40].

In light of what afore mentioned, it may be concluded that force expressed by boxers blows and expression of variables depending on that force (power ...) may be influenced by the presence, the nature as well as the thickness of the bandages and the gloves donned by the boxers.

\section{9) Dietary Behavior}

A study aimed to examine the effects of serial reduction in energy and fluid intakes utilized eight amateur boxers [age: $23.6 \pm 3.2$ years; height: $175 \pm 5 \mathrm{~cm}$; and body mass $73.3 \pm 8.3 \mathrm{~kg}$ (means $\pm \mathrm{SD}$ )]. Subjects acted as their own controls. A 9-day period of normal dietary behavior separated a 5-day normal diet trial and a 5-day restricted diet trial. During each 5-day trial, body mass has been recorded on the days 1,3 and 5; simulated boxing bouts took place on the days 3 and 5. Each boxing bout consisted of 3-minutes rounds with 1-minute recovery. Energy and fluid intakes were significantly $(\mathrm{p}<0.05)$ lower during the restricted diet trial than the normal diet trial.

Compared to the normal diet trial bouts, during the restricted diet trial bouts, boxers body mass was $3 \%$ lower $(\mathrm{p}<0.05)$ but there were no statistical significance in the punching force differences that were $3.2 \%$ (first bout) and $4.6 \%$ (second bout) lower.

It should be borne in mind that boxing performance does not rely only on punching force. Boxers and other boxing contributors must take into account the fact that strategies used to make weight by boxers have been found [41] associated with a negative mood profile and a poor performance.

10) Massage

An interdisciplinary study [42] was undertaken with the aim of investigating 
the effect of massage on blood lactate removal after amateur boxing performance and to examine massage effects on perceived recovery and repeated sports performance.

Boxers initially completed a boxing performance, next received either a massage or a passive rest intervention before completing a second performance.

Massage was found unable to prevent a decrement in repeated performance and not to have detrimental effects on performance.

However, massage intervention significantly $(\mathrm{p}<0.01)$ increased perceptions of recovery, compared with the passive rest intervention.

\section{1) Additional Force Values}

The peak force on impact of a straight punch delivered by Frank Bruno, a World ranked British professional heavyweight boxer, to an instrumented padded target mass suspended as a ballistic pendulum was $4096 \mathrm{~N}$ (0.4 ton), attained within $14 \mathrm{~ms}$ of contact and represented a blow to the human head up to $6320 \mathrm{~N}$ (0.63 ton) [43]. The transmitted impulse generated the target head acceleration of $520 \mathrm{~m} \cdot \mathrm{s}^{-2}(=53 \mathrm{~g})$.

As mentioned by the study authors, the results generalization cannot be applied to the boxing population, the scope of the work being limited to only one subject.

\subsubsection{Velocity}

Velocity, also known as speed [44], is the change in position over time [45].

The following are velocity values shown after studies dealing with the subject.

In four experienced boxers, average velocities at contact ranged from 5.9 to $8.2 \mathrm{~m} \cdot \mathrm{s}^{-1}$ with peak velocities of 6.6 to $12.5 \mathrm{~m} \cdot \mathrm{s}^{-1}$ reached 8 to $21 \mathrm{~ms}$ prior to hand/glove contact with the bag; the comparison of gloved vs. barehanded punches kinematics showed only few differences while comparison of hooks and jabs yielded significant differences in shoulder and wrist velocities, elbow angle excursions, and elbow angular velocities [46].

The hook produced the highest change in hand velocity $\left(11.0 \pm 3.4 \mathrm{~m} \cdot \mathrm{s}^{-1}\right)$ when 11 Olympic boxers weighing 51 to $130 \mathrm{~kg}(112-285 \mathrm{lb})$ landed hooks, uppercuts and straight punches to the forehead and jaw of the Hybrid III dummy [34].

Average hand velocity of 9.14 (SD 2.06) $\mathrm{m} \cdot \mathrm{s}^{-1}$ was attained when seven Olympic boxers from five weight classes delivered 18 straight punches to the frangible face of the Hybrid III dummy [30].

\subsubsection{Power}

Power is defined as the rate that work is being done [45] where work is the product of the force exerted on an object and the distance the object moves in the direction in which the force is exerted [20].

A study aimed to evaluate the influence of vibration on the mechanical properties of arm flexors utilized 12 international level boxers from the Italian national team still engaged in regular boxing training [47]. 
The results showed statistically significant average power enhancement in vibration-treated arms.

\subsubsection{Additional Ergometry Values}

Various values of a heavyweight professional boxer (only one subject, Frank Bruno) punch were determined from the moment the blow was committed-that is, from the moment the elbow first began to extend-until the completion of the follow through [43]. Here are some of them: duration of the trunk advance before start $(201 \mathrm{~ms})$, velocity of trunk and fist before start $\left(1.0 \mathrm{~m} \cdot \mathrm{s}^{-1}=2.2 \mathrm{mph}\right)$, time taken from start of punch to impact $(100 \mathrm{~ms})$, distance punch travels from start to impact $(490 \mathrm{~mm})$, distance of follow through $(110 \mathrm{~mm})$, velocity of fist at impact $\left(8.9 \mathrm{~m} \cdot \mathrm{s}^{-1}=20 \mathrm{mph}\right)$, and residual velocity after impact $\left(1.8 \mathrm{~m} \cdot \mathrm{s}^{-1}\right)$.

As mentioned by the study authors, the results generalization cannot be applied to the boxing population, the scope of the work being limited to only one subject.

\subsection{Suggestions to Boxing Contributors Reminder}

Before deciding the weight division in which they would like to belong during the coming competition, boxers would better remember that body weight reached $7.0 \% \pm 0.8 \%$ at the end of a 21 day pre-contest period but only one day recovery yielded an increase of $4.4 \% \pm 3.3 \%$.

To make their weight limits before competition, boxers would better lose weight by decreasing superfluous body fat instead of cutting down on fluids. Nevertheless, female boxers must take into account the fact that low body fat mass is related to oligomenorrhea.

Boxers and other boxing contributors must take into account the fact that strategies used to make weight by boxers have been found associated with a negative mood profile and a poor performance.

Training techniques aimed to increase punch effective mass, and thus punch force, must be developed.

In the aim of foreseeing and thus preventing a possible fall in a boxer ranking, girth measurement should be made at the beginning of a sporting season with the purpose of comparing to subsequent measurements.

Vibration treatment as well as boxing tasks may increase boxer skeletal muscles power but boxing tasks have the advantage of improving at the same time boxing skills.

To adapt the somatotype of a practitioner to the ideal somatotype of boxing, 1) endomorphy could: a) be decreased by increasing aerobic exercise volume and/or reducing food intake, but b) increased via calorie intake increase, while $2^{\circ}$ mesomorphy may be increased via strength training.

A retrospective analysis of handgrip strength measurement values is one of the tools that may be used by a coach to assess the suitability of a boxer to meet competition demands.

Boxers would better use thick hand bandages to which they must add diachylon pieces before donning appropriate boxing gloves. 
Boxers may adopt the above mentioned stance for sound energy management, balance, efficient performance and safety.

The boxer who lacks endurance would better try to knock out his opponent early in the battle. With that purpose, hitting the head is more helpful to the boxer than hitting the opponent's body.

Boxers should extend the leg of the same body side while, using the rear hand, they land a straight blow to the opponent's head.

After the use of a straight punch as preparation for knocking out the opponent, straight or uppercut punches may be used but it is preferable to use a hook.

When the intention is other than hitting hard, the boxer should use preferably straight punches and reserve uppercuts and especially hooks either for discouraging the opponent from attacking or in the intent to knock out the opponent.

When the intention of the boxer is either discouraging the opponent from attacking or intending to knock out the opponent, the boxer should use the rear fist and use the lead hand when the intention is other.

In the case that maximum punch force value is very low in a boxer, compared to the mean value, the boxer may improve his value by using intention influence on punching force.

Before performing further performance, intervention other than massage must be used instead of massage if the aim is prevention of repeated performance decrement.

\section{Systemic Responses and Adaptations}

Systemic Responses and Adaptations are going to be dealt with next.

\section{Recovery, Weight Control, Dietary Supplementation, Childhood, Gender, Altitude, Life Expectancy and Faith}

Recovery, Weight Control, Dietary Supplementation, Childhood, Gender, Altitude, Life Expectancy and Faith are going to be dealt with next.

\section{Conflicts of Interest}

The author declares no conflicts of interest regarding the publication of this paper.

\section{References}

[1] Harman, E. and Garhammer, J. (2008) Administration, Scoring, and Interpretation of Selected Tests. In: Baechle, T.R. and Earle, R.W., Eds., Essentials of Strength Training and Conditioning, 3rd Edition, Human Kinetics, Champaign, IL, 249-292.

[2] López-Silvarrey Varela, F.J. and Calderón Montero, F.J. (1996) Cineantropometría. In: Legido Arce, J.C., Segovia Martínez, J.C. and López-Silvarrey Varela, F.J., Eds., Manual de Valoración Funcional, Ediciones Eurobook S.L., Madrid, 53-83.

[3] Summers, D. (2007) Longman Dictionary of Contemporary English. 4th Edition, Pearson Education, Harlow.

[4] Bouttier, J.-C. and Lustyk, J.-P. (1990) La Boxe. Éditions Denoël, Paris. 
[5] Hamer, P. and Bloomfield, J. (2009) Posture. In: Ackland, T.R., Elliot, B.C. and Bloomfield, J., Eds., Applied Anatomy and Biomechanics in Sport, Human Kinetics, Champaign, IL, 103-117.

[6] Kittel, R., Misch, K., Schmidt, M., Ellwanger, S., Bittmann, F. and Badtke, G. (2005) Specific Effects of Boxing on Functional Parameters of the Locomotor System [Article in German]. Sportverletzung Sportschaden: Organ der Gesellschaft für OrthopädischTraumatologische Sportmedizin, 19, 146-150. https://doi.org/10.1055/s-2005-858292

[7] Kerr, D.A. and Stewart, A.D. (2009) Body Composition in Sport. In: Ackland, T.R., Elliot, B.C. and Bloomfield, J., Eds., Applied Anatomy and Biomechanics in Sport, Human Kinetics, Champaign, IL, 67-86.

[8] Smith, M.S. (2006) Physiological Profile of Senior and Junior England International Boxers. Journal of Sports Science and Medicine, CSSI, 74-89.

[9] American College of Sports Medicine (2010) ACSM's Guidelines for Exercise Testing and Prescription. 8th Edition, Lippincott Williams \& Wilkins, Baltimore, MD.

[10] Reilly, T. (1990) The Racquet. In: Reilly, T., Secher, N., Snell, P. and Williams, C., Eds., Physiology of Sports, E \& FN Spon, London, 337-369.

[11] Reilly, T. (1990) Football. In: Reilly, T., Secher, N., Snell, P. and Williams, C., Eds., Physiology of Sports, E \& FN Spon, London, 371-425.

[12] Fleck, S.J. (1983) Body Composition of Elite American Athletes. The American Journal of Sports Medicine, 11, 398-403. https://doi.org/10.1177/036354658301100604

[13] Trutschnigg, B., Chong, C., Habermayora, L., Karelis, A.D. and Komorowsky, J. (2008) Female Boxers Have High Bone Mineral Density Despite Low Body Fat Mass, High Energy Expenditure, and a High Incidence of Oligomenorrhea. Applied Physiology, Nutrition, and Metabolism, 33, 863-869. https://doi.org/10.1139/H08-071

[14] Williams, C. (1990) Metabolic Aspects of Exercise. In: Reilly, T., Secher, N., Snell, P. and Williams, C., Eds., Physiology of Sports, E \& FN Spon, London, 3-40.

[15] Olds, T.S. and Tomkinson, G.R. (2009) Absolute Body Size. In: Ackland, T.R., Elliot, B.C. and Bloomfield, J., Eds., Applied Anatomy and Biomechanics in Sport, Human Kinetics, Champaign, IL, 29-46.

[16] Guidetti, L., Musulin, A. and Baldari, C. (2002) Physiological Factors in Middleweight Boxing Performance. The Journal of Sports Medicine and Physical Fitness, 42, 309-314.

[17] Carter, J.E.L. and Ackland, T.R. (2009) Somatotype in Sport. In: Ackland, T.R., Elliot, B.C. and Bloomfield, J., Eds., Applied Anatomy and Biomechanics in Sport, Human Kinetics, Champaign, IL, 47-66.

[18] Khanna, G.L. and Manna, I. (2006) Study of Physiological Profile of Indian Boxers. Journal of Sports Science and Medicine, 5, 90-98.

[19] Reilly, T. (1990) Swimming. In: Reilly, T., Secher, N., Snell, P. and Williams, C., Eds., Physiology of Sports, E \& FN Spon, London, 217-257.

[20] Harman, E. (2008) Biomechanics of Resistance Exercise. In: Baechle, T.R. and Earle, R.W., Eds., Essentials of Strength Training and Conditioning, 3rd Edition, Human Kinetics, Champaign, IL, 65-91.

[21] Weineck, J. (1990) Functional Anatomy in Sports. 2nd Illustrated Edition, Mosby Year Book, St. Louis, MO.

[22] Reilly, T. and Secher N. (1990) Physiology of Sports: An Overview. In: Reilly, T., 
Secher, N., Snell, P. and Williams, C., Eds., Physiology of Sports, E \& FN Spon, London, 465-485.

[23] Dyson, R., Smith, M.S., Martin, C. and Fenn, L. (2007) Muscular Recruitment During Rear Hand Punches Delivered at Maximal Force and Speed by Amateur Boxers. Proceedings of International Conference of Biomechanics in Sport, XXV ISBS Symposium 2007, Ouro Preto-Brazil, 591-594.

http://w4.ub.uni-konstanz.de/cpa/article/viewFile/552/491

[24] Lippert, L.S. (2000) Clinical Kinesiology for Physical Therapist Assistants. 3rd Edition, F.A. Davis Company, Philadelphia, PA.

[25] Amell, T. (2004) Shoulder, Elbow, and Forearm Strength. In: Kumar, S., Ed., Muscle Strength, CRC Press LLC, Boca Raton, FL, 227-246.

[26] Andres, R.O. (2004) Pushing and Pulling Strength. In: Kumar, S., Ed., Muscle Strength, CRC Press LLC, Boca Raton, FL, 345-365.

[27] Hecht, E. (1999) Physique. Éditions De Boeck Université, Bruxelles.

[28] Plisk, S.S. (2008) Speed, Agility, and Speed-Endurance Development. In: Baechle, T.R. and Earle, R.W., Eds., Essentials of Strength Training and Conditioning, 3rd Edition, Human Kinetics, Champaign, IL, 457-485.

[29] Klausen, K. (1990) Strength and Weight-Training. In: Reilly, T., Secher, N., Snell, P. and Williams, C., Eds., Physiology of Sports, E \& FN Spon, London, 41-67.

[30] Walilko, T.J., Viano, D.C. and Bir, C.A. (2005) Biomechanics of the Head for Olympic Boxer Punches to the Face. British Journal of Sports Medicine, 39, 710-719. https://doi.org/10.1136/bjsm.2004.014126

[31] Bell, G.J. and Syrotuik, D.G. (2004) Physiology and Biochemistry of Strength Generation and Factors Limiting Strength Development in Skeletal Muscle. In: Kumar, S., Ed., Muscle Strength, CRC Press LLC, Boca Raton, FL, 13-32.

[32] Smith, M.S., Dyson, R.J., Hale, T. and Janaway, L. (2000) Development of A Boxing Dynamometer and Its Punch Force Discrimination Efficacy. Journal of Sports Sciences, 18, 445-450. https://doi.org/10.1080/02640410050074377

[33] Kumar, S. (2004) Trunk and Lifting Strength. In: Kumar, S., Ed., Muscle Strength, CRC Press LLC, Boca Raton, FL, 263-344.

[34] Viano, D.C., Casson, I.R., Pellman, E.J., Bir, C.A., Zhang, L., Sherman, D.C. and Boitano, M.A. (2005) Concussion in Professional Football: Comparison with Boxing Head Impacts-Part 10. Neurosurgery, 57, 1154-1172. https://doi.org/10.1227/01.NEU.0000187541.87937.D9

[35] Tyldesley, B. and Grieve, J.I. (2002) Muscles, Nerves \& Movement in Human Occupation. Blackwell Science, Oxford.

[36] Oates, J.C. (2006) On Boxing. Harper Perennial Modern Classics, New York.

[37] Anonyme (2009) Mechanics and Pathomechanics of Muscle Activity at the Knee. In: Oatis, C.A., Ed., Kinesiology: The Mechanics and Pathomechanics of Human Movement, 2nd Edition, Lippincott Williams \& Wilkins, Baltimore, MD, 767-790.

[38] Schmidt-Olsen, S., Jensen, S.K. and Mortensen, V. (1990) Amateur Boxing in Denmark. The Effect of Some Preventive Measures. The American Journal of Sports Medicine, 18, 98-100. https://doi.org/10.1177/036354659001800117

[39] Kim, B.J. and Bishu, R.R. (2004) Grasp at Submaximal Strength. In: Kumar, S., Ed., Muscle Strength, CRC Press LLC, Boca Raton, FL, 213-225.

[40] Roy, B., Bernier-Cardou, M., Cardou, A. and Plamondon, A. (1984) Influence of Bandages on the Strength of Impact of Punches in Boxing [Article in French]. Journal 
Canadien des Sciences Appliquées au Sport, 9, 181-187.

[41] Hall, C.J. and Lane, A.M. (2001) Effects of Rapid Weight Loss on Mood and Performance among Amateur Boxers. British Journal of Sports Medicine, 35, 390-395. https://doi.org/10.1136/bjsm.35.6.390

[42] Hemmings, B., Smith, M., Graydon, J. and Dyson, R. (2000) Effects of Massage on Physiological Restoration, Perceived Recovery, and Repeated Sports Performance. British Journal of Sports Medicine, 34, 109-114. https://doi.org/10.1136/bjsm.34.2.109

[43] Atha, J., Yeadon, M.R., Sandover, J. and Parsons, K.C. (1985) The Damaging Punch. British Medical Journal (Clinical Research Edition), 291, 1756-1757. https://doi.org/10.1136/bmj.291.6511.1756

[44] Anonyme (2009) Characteristics of Normal Gait and Factors Influencing It. In: Oatis, C.A., Ed., Kinesiology: The Mechanics and Pathomechanics of Human Movement, 2nd Edition, Lippincott Williams \& Wilkins, Baltimore, MD, 892-917.

[45] Karduna, A.R. (2009) Introduction to Biomechanical Analysis. In: Oatis, C.A., Ed., Kinesiology: The Mechanics and Pathomechanics of Human Movement, 2nd Edition, Lippincott Williams \& Wilkins, Baltimore, MD, 3-20.

[46] Whiting, W.C., Gregor, R.J. and Finerman, G.A. (1988) Kinematic Analysis of Human Upper Extremity Movements in Boxing. The American Journal of Sports Medicine, 16, 130-136. https://doi.org/10.1177/036354658801600207

[47] Bosco, C., Cardinale, M. and Tsarpela, O. (1999) Influence of Vibration on Mechanical Power and Electromyogram Activity in Human Arm Flexor Muscles. European Journal of Applied Physiology and Occupational Physiology, 79, 306-311. https://doi.org/10.1007/s004210050512 